\title{
ANALISIS KEMAMPUAN DAN KEMAUAN MEMBAYAR PASIEN RAWAT INAP DI RS PKU MUHAMMADIYAH BANTUL
}

\author{
Ahmad Ahid Mudayana, Heni Rusmitasari \\ Fakultas Kesehatan Masyarakat, Universitas Ahmad Dahlan, Yogyakarta \\ Email: ahidfkm@gmail.com
}

\begin{abstract}
Background: The number of treatment options for making competition among hospitals increasingly stringent anyway though not the business competition. The amount of this option makes every hospital must calculate the unit cost of each so as to make the right policy in determining the hospital tariffs. PKU Muhammadiyah Bantul is Muhammadiyah owned hospitals have a social mission in providing helath services to the community. The social mission of making hospitals PKU Muhammadiyah Bantul in setting accordance rates with ability to pay of the community. This is because the target consumer PKU Muhammadiyah Bantul majority of the lower middle class people. Currently PKU Muhammadiyah Bantul is developing the building, including increasing the number of beds to 300. Increasing the number of beds will make PKU Muhammadiyah Bantul as the largest Muhammadiyah hospital in Yogyakarta. The existence of this development will be made possible due to changes in the level of rates increasing operational needs. Background of the researchers interested in studying the patient's willingness and ability to pay in PKU Muhammadiyah Hospital in Bantul.

Methods: This was analytic research, using cross sectional design. The sample in this study amounted to 87 respondents.

Results: Based on the analysis showed that patient has the ability to pay an average of 100 033. The average willingness to patients high category in the amount of 71.26 percent.

Conclusions: 1) The average ability to pay inpatients Rp 100 033, estimated for three days. 2) In order to conduct the promotion of hospital managers in an appropriate manner, for example by offering affordable rates to the public.
\end{abstract}

Keywords: analysis, willingness to pay, ability to pay

\begin{abstract}
Abstrak
Latar Belakang: Semakin banyaknya pilihan untuk berobat menjadikan kompetisi antar rumah sakit semakin ketat pula meskipun bukan kompetisi bisnis. Banyaknya pilihan ini menjadikan setiap rumah sakit harus menghitung unit cost masing-masing sehingga mampu membuat kebijakan yang tepat dalam menentukan tarif rumah sakit. PKU Muhammadiyah Bantul merupakan rumah sakit milik Muhammadiyah yang memiliki misi sosial didalam memberikan pelayanan kesehatan kepada masyarakat. Misi sosial tersebut menjadikan rumah sakit PKU Muhammadiyah Bantul dalam menetapkan tarif harus sesuai dengan kemampuan masyarakat. Hal ini dikarenakan sasaran konsumen PKU Muhammadiyah Bantul mayoritas merupakan masyarakat kalangan menengah ke bawah. Saat ini PKU Muhammadiyah Bantul sedang melakukan pengembangan gedung, termasuk penambahan jumlah tempat tidur menjadi 300 . Penambahan jumlah tempat tidur ini akan menjadikan PKU Muhammadiyah Bantul sebagai rumah sakit Muhammadiyah terbesar se-DIY. Adanya pengembangan ini akan dimungkinkan terjadi perubahan tarif karena tingkat kebutuhan operasional yang semakin meningkat. Dari latar belakang tersebut peneliti tertarik untuk meneliti kemauan dan kemampuan membayar pasien di RS PKU Muhammadiyah Bantul.

Metode: Jenis penelitian ini adalah penelitian analitik. Rancangan penelitian menggunakan cross sectional. Sampel dalam penelitian ini berjumlah 87 responden.

Hasil: Berdasarkan analisis yang sudah dilakukan didapatkan hasil bahwa kemampuan membayar pasien memiliki rata-rata sebesar 100.033. Sedangkan rata-rata kemauan membayar pasien termasuk kedalam kategori tinggi yaitu sebesar 71,26 persen.
\end{abstract}

Analisis Kemampuan dan Kemauan Membayar Pasien Rawat Inap .... (Ahmad Ahid Mudayana) 
Kesimpulan: 1.) Rata-rata kemampuan membayar pasien rawat inap sebesar Rp 100.033, diperkirakan selama tiga hari. 2.) Agar manajer melakukan promosi rumah sakit dengan cara yang tepat, misalnya dengan menawarkan tarif yang terjangkau untuk masyarakat.

Kata Kunci: analisis, kemauan membayar, kemampuan membayar

\section{Pendahuluan}

Semakin banyaknya pilihan untuk berobat menjadikan kompetisi antar rumah sakit semakin ketat pula meskipun bukan kompetisi bisnis. Banyaknya pilihan ini menjadikan setiap rumah sakit harus menghitung unit cost masing-masing sehingga mampu membuat kebijakan yang tepat dalam menentukan tarif rumah sakit. Salah satu proses untuk menentukan besaran tarif rumah sakit yaitu dengan menilai kemauan dan kemampuan membayar pasien. Kemauan membayar pasien harus dihitung karena sebagai pertimbangan manajemen rumah sakit dalam menentukan besaran tarif yang akan dikeluarkan. Tanpa mengetahui kemauan membayar oleh pasien maka dimungkinkan tarif yang dibuat oleh rumah sakit terlalu besar sehingga masyarakat tidak bersedia membayar. Akibatnya, masyarakat akan memilih rumah sakit yang lain. Penentuan tarif rumah sakit juga ditentukan oleh kemampuan membayar pasien. Apabila tarif yang dibuat terlalu besar maka dimungkinkan masyarakat tidak mampu membayar sehingga mereka memilih untuk menggunakan fasilitas kesehatan yang lain.

Rumah sakit PKU Muhammadiyah Bantul merupakan rumah sakit milik Muhammadiyah yang memiliki misi sosial di dalam memberikan pelayanan kesehatan kepada masyarakat. Misi sosial tersebut menjadikan rumah sakit PKU Muhammadiyah Bantul dalam menetapkan tarif harus sesuai dengan kemampuan masyarakat. Hal ini dikarenakan sasaran konsumen PKU Muhammadiyah Bantul mayoritas merupakan masyarakat kalangan menengah ke bawah. Saat ini PKU Muhammadiyah Bantul sedang melakukan pengembangan gedung, termasuk penambahan jumlah tempat tidur menjadi 300. Penambahan jumlah tempat tidur ini akan menjadikan PKU Muhammadiyah Bantul sebagai rumah sakit Muhammadiyah terbesar se-DIY.

Pengembangan gedung yang dilakukan oleh manajemen rumah sakit menjadikan manajemen harus berpikir ulang dalam menetapkan tarif agar masyarakat yang selama ini sudah loyal tidak berpindah karena biaya yang semakin mahal. Adanya pengembangan ini akan dimungkinkan terjadi perubahan tarif karena tingkat kebutuhan operasional yang semakin meningkat. Dari latar belakang tersebut peneliti tertarik untuk meneliti kemauan dan kemampuan membayar pasien di RS PKU Muhammadiyah Bantul.

\section{Metode Penelitian}

Jenis penelitian ini adalah penelitian analitik. Rancangan penelitian menggunakan cross sectional. Subjek dalam penelitian adalah pasien rawat inap di RS PKU Muhammadiyah yang berjumlah 87 pasien. 


\section{Hasil Penelitian dan Pembahasan}

\section{A. Hasil Penelitian}

1) Karakteristik Responden

Tabel 1. Tingkat pendidikan responden

\begin{tabular}{ccc}
\hline Pendidikan & Jumlah & Persentase (\%) \\
\hline SD & 33 & 38,4 \\
SMP & 24 & 28,5 \\
SMA & 29 & 33,0 \\
S1/PT & 1 & 0,1 \\
Jumlah & 87 & 100 \\
\hline
\end{tabular}

Berdasarkan Tabel 1 mayoritas responden memiliki pendidikan yang rendah $(38,4 \%)$ karena hanya lulusan bahkan tidak tamat SD. Sedangkan untuk yang berpendidikan tinggi tingkat sarjana paling rendah. Hal ini dikarenakan responden yang diambil yaitu pasien kelas III dirumah sakit.

Tabel 2. Karakteristik pekerjaan responden

\begin{tabular}{ccc}
\hline Pekerjaan & Jumlah & Persentase (\%) \\
\hline Buruh/IRT & 61 & 70,11 \\
Guru & 1 & 1,16 \\
Wiraswasta & 13 & 14,94 \\
Karyawan & 12 & 13,79 \\
Jumlah & 87 & 100 \\
\hline
\end{tabular}

Tabel 2 memperlihatkan bahwa mayoritas responden bekerja sebagai buruh $(70,11 \%)$. Sedangkan responden yang bekerja sebagai guru hanya $1,16 \%$ atau terendah. RS PKU Muhammadiyah Bantul yang memang berkonsentrasi untuk membantu masyarakat kurang mampu menjadikan pasien yang berobat ke rumah sakit mayoritas dari kalangan menengah kebawah.

Tabel 3. Jumlah pendapatan responden

\begin{tabular}{ccc}
\hline Pendapatan & Jumlah & Persentase (\%) \\
\hline < 1 Juta & 57 & 65,52 \\
>1 Juta & 30 & 34,48 \\
Jumlah & 87 & 100 \\
\hline
\end{tabular}

Tabel 3 diatas menunjukkan bahwa mayoritas responden memiliki pendapatan dibawah satu juta rupiah (65,52\%). Hal ini dikarenakan mayoritas pekerjaan responden sebagai buruh. Selain itu, tingkat pendidikan mayoritas lulusan bahkan tidak tamat SD.

Tabel 4. Keikutsertaan Asuransi

\begin{tabular}{ccc}
\hline Asuransi & Jumlah & Persentase (\%) \\
\hline Ya & 74 & 85,06 \\
Tidak & 13 & 14,94 \\
Jumlah & 87 & 100 \\
\hline
\end{tabular}

Tabel 4 diatas menunjukkan bahwa mayoritas responden menjadi anggota asuransi $(85,06 \%)$. Asuransi yang diikuti oleh responden beragam 
mulai dari Jamkesmas, Jamkesda dan Babel. Sedangkan sisanya tidak mengikuti asuransi kesehatan yaitu sebanyak 14,94\%.

\section{2) Kemampuan membayar pasien}

Tabel 5. Kemampuan membayar pasien

\begin{tabular}{cc}
\hline Kemampuan & Jumlah (Rp) \\
\hline Terendah & 9.333 \\
Tertinggi & 385.000 \\
Rata-rata & 100.033 \\
\hline
\end{tabular}

Tabel 5 menunjukkan bahwa kemampuan membayar pasien memiliki rentang perbedaan yang sangat tinggi. Hal ini bisa dilihat dari kemampuan terendah yaitu sebesar Rp.9.333,- dibanding dengan kemampuan tertinggi yaitu sebesar Rp. 385.000. Kemampuan membayar ini merupakan perkiraan jika pasien dirawat inap selama tiga hari. Dari tabel tersebut juga memperlihatkan bahwa rata-rata kemampuan membayar pasien sebesar Rp.100.033,-.

\section{3) Kemauan membayar pasien}

Tabel 6. Kemauan membayar biaya kamar

\begin{tabular}{ccc}
\hline Kemauan & Jumlah & Persentase (\%) \\
\hline Rendah & 53 & 60,92 \\
Tinggi & 34 & 39,08 \\
Jumlah & 87 & 100 \\
\hline
\end{tabular}

Tabel 6 diatas menunjukkan bahwa kemauan mayoritas pasien untuk membayar biaya layanan kamar masih rendah. Hal ini menunjukkan bahwa mayoritas pasien masih keberatan dengan biaya layanan kamar yang saat ini ditetapkan oleh pihak rumah sakit, sehingga mereka masih menginginkan adanya penurunan biaya layanan kamar.

Tabel 7. Kemauan membayar biaya makan

\begin{tabular}{ccc}
\hline Kemauan & Jumlah & Persentase (\%) \\
\hline Rendah & 23 & 26,44 \\
Tinggi & 64 & 73,56 \\
Jumlah & 87 & 100 \\
\hline
\end{tabular}

Tabel 7 diatas menunjukkan bahwa kemauan membayar pasien terhadap biaya makan selama dirawat inap tinggi (73,56\%). Mayoritas responden bersedia membayar biaya makan yang ditetapkan oleh pihak rumah sakit. Meskipun 26,44\% responden masih merasa keberatan dengan biaya yang saat ini ditetapkan.

Tabel 8. Kemauan membayar jasa dokter

\begin{tabular}{ccc}
\hline Kemauan & Jumlah & Persentase (\%) \\
\hline Rendah & 7 & 8,05 \\
Tinggi & 80 & 91,95 \\
Jumlah & 87 & 100 \\
\hline
\end{tabular}


Tabel 8 menunjukkan bahwa kemauan pasien untuk membayar jasa dokter yang ditetapkan oleh pihak rumah sakit tinggi (91,95\%). Hal ini menjadi menarik karena berbanding terbalik dengan kemauan pasien untuk biaya layanan kamar. Padahal biaya layanan kamar merupakan beban tertinggi yang harus ditanggung oleh rumah sakit dalam hal beban operasional dibanding beban biaya yang lain.

Tabel 9. Rata-rata Kemauan membayar pasien

\begin{tabular}{ccc}
\hline Kemauan & Jumlah & Persentase (\%) \\
\hline Rendah & 25 & 28,74 \\
Tinggi & 62 & 71,26 \\
Jumlah & 87 & 100 \\
\hline
\end{tabular}

Tabel 9 menunjukkan bahwa mayoritas pasien tingkat kemauan membayar biaya rawat inap yang ditetapkan oleh pihak rumah sakit tinggi yaitu $71,26 \%$. Meskipun dibeberapa kategori biaya rawat inap masih ada yang tingkat kemauan membayarnya rendah seperti biaya layanan kamar.

\section{B. Pembahasan}

\section{a) Kemampuan Membayar Pasien}

Penelitian ini didapatkan bahwa kemampuan pasien dalam membayar jasa pelayanan rumah sakit memiliki rata-rata Rp 100.033 per tiga hari rawat inap dengan biaya terendah sebesar $\mathrm{Rp} 9.333$ dan biaya terendah sebesar $\mathrm{Rp}$ 385.000. Penelitian terdahulu, mendapatkan hasil bahwa rata-rata kemampuan membayar rawat inap pasien kelas III sebesar Rp 279.985 perharinya, yang berarti untuk kelas I, II, dan VIP lebih tinggi. ${ }^{1}$ Hasil penelitian sebelumnya ini berbeda jauh dengan hasil penelitian yang telah peneliti lakukan yang didapatkan hasil sebesar Rp 100.033 per tiga hari rawat inap. Hal ini mungkin disebabkan karena jumlah pendapatan responden yang kurang dari 1 juta setiap bulannya. Pendapatan yang rendah bisa disebabkan karena tingkat pendidikan yang mayoritas tidak tinggi yaitu hanya tamat SD, sehingga akan berdampak pada jenis pekerjaan dan pendapatan.

Meskipun kemampuan membayar pasien sebesar Rp 100.003 dan menggunakan asuransi kesehatan, diharapkan pelayanan yang diberikan oleh pihak rumah sakit dapat berkualitas atau sejajar dengan pelayanan yang diberikan kepada pasien umum. Apabila dilihat dari tingkat kemampuan membayar pasien yang rata-ratanya sebesar Rp 100.033, maka pihak rumah sakit harus dapat menetapkan tarif pelayanan yang dapat terjangkau oleh masyarakat atau pasien. Sehingga masyarakat akan menggunakan ulang jasa yang sudah diberikan. Penetapan tarif atau informasi biaya pada rumah sakit merupakan salah satu cara untuk menarik pasien agar bersedia berobat di rumah sakit tersebut.

Harga merupakan elemen bauran pemasaran yang menghasilkan pendapatan dan dapat berubah dengan cepat. Harga dapat digunakan sebagai salah satu strategi untuk meciptakan dan menangkap nilai pelanggan serta membangun hubungan baik dengan pelanggan. Selain tarif, cara pembayaran yang mudah dan mudah dimengerti oleh pasien akan membuat pasien merasa dipermudah atau merasa mendapatkan pelayanan yang baik dari pihak rumah sakit. Kerjasama pihak rumah sakit dengan 
asuransi atau jeminan kesehatan pemerintah juga akan menarik pasien untuk menggunakan jasa pelayanan di rumah sakit tersebut. ${ }^{2}$

\section{b) Kemauan Membayar Pasien}

Pada penelitian ini diketahui bahwa kemampuan pasien dalam membayar jasa pelayanan rumah sakit yang didapatkan selama perawatan termasuk dalam kategori tinggi sebanyak 62 responden $(71,26 \%)$ atau memiliki kemauan yang tinggi dalam membayar jasa pelayanan.

Tabel 4 menunjukkan bahwa sebanyak 74 pasien $(85,06$ persen) ikut masuk dalam asuransi kesehatan seperti Jamkesmas, Jamkesda, dan asuransi kesehatan lainnya yang berarti bahwa biaya pengobatan hampir keseluruhan dibiayai oleh pemerintah. Meskipun biaya ditanggung oleh pemerintah pasien memiliki tingkat kemauan untuk membayar yang tinggi.

Pasien yang berobat menggunakan jaminan kesehatan bersedia membayar pengobatan, ini sesuai dengan penelitian yang pernah dilakukan sebelumnya menyebutkan bahwa tidak ada pengaruh antara kepemilikan asuransi dengan kemauan membayar pelayanan rumah sakit oleh pasien. Dalam penelitiannya diketahui bahwa pasien yang memiliki asuransi bersedia atau memiliki kemauan untuk membayar pelayanan yang sudah didapatkan. $^{3}$

Pendapatan keluarga mempengaruhi kemauan pasien untuk membayar jasa pengobatan yang sudah diberikan. Apabila pendapatan pasien masih dirasa kurang maka enggan untuk membayar jasa pelayanan atau pengobatan. Berbeda dengan hasil penelitian yang peneliti lakukan, dari hasil statistik dapat diketahui bahwa meskipun pasien mayoritas memiliki pendapatan di bawah 1 juta, tetapi pasien memiliki kemauan yang tinggi untuk membayar jasa pelayanan yang sudah didapatkan. ${ }^{4}$

Adanya kemauan atau kesediaan pasien dalam membayar jasa pelayanan yang diberikan oleh pihak rumah sakit, seharusnya pihak rumah sakit harus dapat lebih meningkatkan lagi kualitas pelayanannya. Dengan adanya kualitas pelayanan yang baik, yang sesuai dengan keinginan pasien maka kepuasan pasien akan terwujud dan jumlah kunjungan pasien lebih meningkat lagi. Kepuasan pasien berhubungan dengan mutu pelayanan. Menurut ${ }^{5}$ dengan mengetahui tingkat kepuasan pasien, manajemen rumah sakit dapat melakukan peningkatan mutu pelayanan. Hal ini sesuai dengan penelitian terdahulu, yang menyatakan bahwa kualitas pelayanan memiliki pengaruh terhadap kepuasan pasien dalam menggunakan jasa rawat inap. ${ }^{6}$

Kualitas jasa pelayanan kesehatan akan sangat ditentukan apabila kebutuhan para pengguna jasa bisa terpenuhi dan diterima tepat waktu. Terdapat dua hal yang harus dipenuhi dalam kualitas jasa yaitu expected services dan perceived services. Jika Jika perceived services sesuai dengan expected services maka jasa pelayanan kesehatan dapat dikatakan berkualitas dan para pengguna jasa pelayanan akan puas. ${ }^{7}$

Penelitian lainnya juga menyebutkan bahwa kepuasan pasien berhubungan dengan minat pemanfaatan ulang pelayanan pengobatan. ${ }^{8}$ Semakin tinggi tingkat kepuasan pasien dalam menerima pelayanan dalam pengobatan maka semakin sering pasien tersebut memanfaatkan ulang jasa pelayanan pengobatan di rumah sakit tersebut. Sama halnya dengan penelitian ${ }^{9}$ yang menyebutkan bahwa hubungan antara persepsi pasien tentang kepuasan pasien dan minat membeli ulang jasa terdapat hubungan yang bermakna, dalam observasinya asuhan keperawatan masuk kategori cukup tetapi pasien merasa puas dan berminat membeli ulang jasa asuhan keperawatan tersebut. 
Penelitian terdahulu menyebutkan bahwa aspek yang mempengaruhi kepuasan pasien adalah kesembuhan, ketersediaan obat, keleluasaan pribadi (privasi), kebersihan, informasi menyeluruh, waktu tunggu, fasilitas lingkungan fisik, dan biaya pelayanan secara menyeluruh. ${ }^{10}$

\section{Simpulan dan Saran}

\section{A. Simpulan}

a. Rata-rata kemampuan membayar pasien rawat inap sebesar Rp 100.033, diperkirakan selama tiga hari.

b. Kemauan pasien untuk membayar perawatan dirawat inap termasuk dalam kategori tinggi, meskipun mayoritas pasien menggunakan asuransi kesehatan.

c. Mayoritas kemauan pasien untuk membayar kamar masih rendah.

\section{B. Saran}

a. Agar pimpinan menetapkan tarif pelayanan rumah sakit yang sesuai dengan kemampuan masyarakat.

b. Agar manajer melakukan promosi rumah sakit dengan cara yang tepat, misalnya dengan menawarkan tarif yang terjangkau untuk masyarakat.

c. Agar meningkatkan pelayanan kamar dari segi fasilitas kamar maupun pelayanannya.

\section{Daftar Pustaka}

1. Waty, PLA., Suarjana, K., The Analysis of ability and Willingness to Pay of Inpatients in Kapal badung Hospital, Artikel Community Health, vol/no: 1(1), pp. 48-53, 2013.

2. Juhariah, S., Tita, H., Fatchur, R., Pengalaman Pasien Dirawat Inap Sebagai Upaya Perencanaan Bauran Pemasaran (Studi Fenomenologi Di Rumah sakit X Kabupaten Malang, Jawa Timur), Jurnal Manajemen Pelayanan Kesehatan, vol/no: 15(03), pp. 147155, 2012.

3. Maharani, A., Wardhani V., Analisis pengaruh kepemilikan asuransi kesehatan Terhadap kemauan membayar produk pelayanan laboratorium, Jurnal Manajemen Pelayanan Kesehatan, vol/no: 14(01), pp. 44-48, 2011.

4. Supriyanto, Y., Analisis Pengaruh Kualitas Pelayanan, Harga, dan Fasilitas Terhadap Kepuasan Pasien Rawat Jalan Di Rumah Sakit Kariadi Semarang, Skripsi, Universitas Diponegoro, Semarang, 2012.

5. Nursalam, Manajemen Keperawata: Aplikasi dalam Praktik Keperawatan Profesional, Edisi III, Salemba Medika, Jakarta, 2013.

6. Nurani, T., Wiyadi, Pengaruh Kualitas Pelayanan Terhadap Kepuasan Pengguna Jasa Rawat Inap Di RSUD Dr Moewardi, Jurnal Ekonomi Manajemen Sumber Daya, vol/no: 13(1), pp. 53-64, 2012.

7. Muninjaya, AAG., Manajemen Mutu Pelayanan Kesehatan, EGC, Jakarta, pp. 239-240, 2013.

8. Solikhah, Hubungan Kepuasan Pasien dengan Minat Pasien dalam Pemanfaatan Ulang Pelayanan pengobatan, Jurnal Manajemen Pelayanan Kesehatan, vol/no: 11(04), pp. 192199, 2008.

9. Andriani, RB., Johan, EP., Sri, W., Analisis Kepuasan Pasien terhadap Asuhan Keperawatan di ruang Rawat Inap RSUD dr. Muwardi Surakarta, vol/no: 02(04), pp. 211 216, 1999.

10. Pohan, IS., Jaminan Mutu Pelayanan Kesehatan: Dasar-dasar Pengertian, Kesaint Blanc, Bekasi, 2003. 
